\section{An analysis on the level of social physical anxiety of students studying for university entrance exam}

\section{Üniversite giriş sınavına hazırlanan öğrencilerin sosyal fizik kaygı düzeyinin

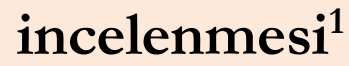

\author{
Dilay Emiroğlu ${ }^{2}$ \\ Murat Özmaden ${ }^{3}$
}

\begin{abstract}
The purpose of this study is to analyze the level of social physical anxiety of students studying for university entrance exam in terms of some variables. This study is based on the general survey model for the specification of social physical anxiety of students studying for university entrance exam and also for the examination of differences on the basis of gender, body mass index, active habit of doing sports, weekly frequency of doing sports, habit of eating fast-food. For data collection, "Personal Information Form" and "Social Physical Anxiety Scale" have been used. Data of this study have been collected during the school year of 2018-2019 from the total number of 401 students studying senior year in high school (in the 12th grade), 216 of which are women $(53.9 \%)$ and 185 of which are men (46.1\%) who study for the university entrance exam at several private educational institutions affiliated with the Directorate of National Education at Efeler district of Aydin. According to the findings resulted from this study, it has been found that the levels of social physical anxiety of students display differences based on the variables of gender, body mass index, active habit of doing
\end{abstract}

Özet

$\mathrm{Bu}$ çalışmada, üniversite sınavına hazırlanan öğrencilerin sosyal fizik kayg1 düzeyinin farklı değişkenler açısından incelenmesi amaçlanmıştır. Üniversite giriş sınavına hazırlanan öğrencilerin sosyal fizik kayg1 düzeyinin belirlenmesi ve cinsiyet, vücut kütle indeksi, spor yapma durumu, haftalık spor yapma günü, fast-food yeme sıklığ1 gibi değişkenler ile incelenmesi açısından genel tarama modelinde bir çalışmadır. Çalışma verilerinin toplanmasında, "Kişisel Bilgi Formu" ve "Sosyal Fizik Kayg1 Envanteri" kullanılmıştır. Çalışmaya, 2018-2019 eğitimöğretim yılında, Aydın ili Efeler ilçesinde Milli Eğitim Müdürlüğü'ne bağlı özel öğretim kurumlarında üniversite giriş sınavlarına hazırlanan 216 kadın ( $\%$ 53.9), 185 erkek ( $\%$ 46.1) olmak üzere toplamda 401 lise son (12.) sınıf öğrencisi katılmıştır. Çalışma sonucunda elde edilen bulgulara göre, öğrencilerin sosyal fizik kayg1 düzeyinin cinsiyet, vücut kütle indeksi, spor yapma durumu, haftallk spor yapma günü değişkenleri açısından farklilık gösterdiği sonucuna ulaşılmıştır. Kadınların sosyal fizik kaygı düzeyinin erkeklerden daha yüksek olduğu, vücut kütle indeksi fazla olan öğrencilerin daha yüksek sosyal fizik kayg1

\footnotetext{
${ }^{1}$ Bu çalışma ikinci yazar danışmanlığında birinci yazar tarafından hazırlanan yüksek lisans tezinden üretilmiştir.

2 M.Sc., dilayemiroglu@,hotmail.com (1) Orcid ID: 0000-0002-2807-0639

3 Doç. Dr., Aydın Adnan Menderes Üniversitesi, Spor Bilimleri Fakültesi, Antrenörlük Eğitimi Bölümü; muratozmaden@gmail.com (D) Orcid ID: 0000-0002-5913-6653
} 
Emiroğlu, D., \& Özmaden, M. (2020). Üniversite giriş sınavına hazırlanan öğrencilerin sosyal fizik kayg1 düzeyinin incelenmesi. Journal of Human Sciences, 17(4), 1034-1046. doi:10.14687/jhs.v17i4.6046

sports and weekly frequency of doing sports. It has been found that the level of social physical anxiety of women are higher than men, students with higher body mass index have higher social physical anxiety and also students doing sports have lower levels of social physical anxiety.

Keywords: High school student, social physical anxiety.

(Extended English summary is at the end of this document) yaşadığı, spor yapan öğrencilerin sosyal fizik kayg1 düzeylerinin daha düşük olduğu bulunmuştur.

Anahtar Kelimeler: Lise öğrencisi, sosyal fizik kayg1.

\section{Giriş}

İnsanlar, yaşadığı sosyal çevrede ilk izlenimin önemli bir kısmını fiziksel görünüşün oluşturduğu algisındadır. Sosyal medya ve kitle iletişim araçları tarafindan yansıtılan; kadınların ince, erkeklerin ise kaslı vücut yapısı kabul edilen bir değer haline getirilmektedir. Toplum, öne sürülen ideal beden kalıplarının dışında kalan kişilerin olumsuz değerlendirileceğini düşünmektedir. Yansıttlan ideal fizik algısının, kişinin duygu ve düşüncelerini önemli bir ölçüde etkilediği görülmektedir.

Kişinin beden algısının oluşumu, çocukluk döneminin sona erip ergenlik döneminin başlaması ile ortaya çıkmakta ve yaşam boyunca sürekli bir değişim ve gelişim içinde devam etmektedir (Yaşartürk ve ark., 2014). İçinde bulundukları dönemde fiziksel olarak nasıl değişimler geçireceğini tam anlamıyla farkında olmayan ergenlerin, çevrede belirtilen uygun beden tasarımının etkisi ile beden algisı bozulmakta ve bu bozukluklar ilerleyen yaşamındaki beden algısını da etkisi altına almaktadır (Uğurlu ve Akın, 2008).

Kişinin görünüşüne aşırı önem vermesi ergenlik döneminin temel özelliklerinden biridir. Günümüzde medyanın etkisi düşünüldügünde, ergenlik çağındaki birey için fiziksel görünümündeki kusurlar önemli bir sorun oluşturmaktadır (Doğan, 2011). Ergenler genellikle kendi görünüşü ile etrafındaki diğer insanların görünüşünü karşılaştırır ve başkaları tarafindan değerlendirilir (Seki ve Dilmaç, 2015).

İnsanların kendi fiziksel görünümü ile ilgili algısının önemi kadar, başkalarının onları nasıl gördüğü ve değerlendirdiği de önemlidir. İnsanlar, içinde bulunduğu sosyal ortamlarda başka insanlar üzerinde olumlu bir izlenim oluşturmak ister ve kendilerini buna göre yönlendirir. Bazı insanların bu konuya, diğerleri ile kıyaslandığında daha çok önem verdiği ve endişeye kapıldığ1 görülmektedir (Pekdağ ve Çoşkun, 2010).

Toplumda dış görünüş ile ilgili ortaya çıkarılan ve benimsenen bu algılar, insanlarda gerçek dışı olan belirli fiziksel ölçülere ulaşması gerektiği baskısını yaratmaktadır. Bireyler bu standartlara ulaşamadığında ya da standartların dışına çıktığında başkaları tarafindan dış görünümünün hoş bulunmadığ1 konusunda yanlış duygu ve düşüncelere kapılabilmekte ve bedeninin başkaları tarafından değerlendirilmesinden endişe duymaktadır. İnsanların fiziksel görüntüsü ile ilgili başka insanların olumsuz değerlendirmelerinden duyduğu endişe "Sosyal Fizik Kaygı" olarak tanımlanmaktadır (Ersöz, 2011).

Hart ve ark. (1989) sosyal fizik kaygıyı, kişinin başkaları tarafindan değerlendirilmesi söz konusu olduğunda bedeniyle ilgili hislerinin kaygiya dönüşmesi olarak tanımlamıştır. Sosyal fizik kayg1 bireylerde farklı durumlarda oluşabilmektedir. Kaygının bu türünde iki alt başlık bulunmaktadır. Bunlardan biri kişinin fiziksel görünüşünden duyduğu rahatsızlık; diğeri ise fiziksel görünüşünün diğer insanlar tarafindan olumsuz şekilde değerlendirilmesinden dolayı duyduğu rahatsızlıktır (Pekdağ ve Çoşkun, 2010). Russell (2002), sosyal fizik kaygı durumunun oluşumunda, 

incelenmesi. Journal of Human Sciences, 17(4), 1034-1046. doi:10.14687/ihs.v17i4.6046

kişinin kendisinin ve başkalarının fiziksel görünüşünün olumsuz değerlendirmesinin rolü olduğunu belirtmiştir. Ayrıca kişiler artan kaygı durumu ile karşılaştığında fiziğini daha fazla olumsuz değerlendirme eğiliminde olmaktadır (Yaşartürk ve ark., 2014). Her bireyin hem pozitif hem negatif duygular yaşamasının mümkün olduğu bilinmektedir. Pozitif duyguların negatif duygulara ağır basması psikolojik iyi oluşun önemli bir noktasıdır (Sarıoğlu, Güngörmüş, Işık, 2019). Buna dayanarak, sürekli olumsuz düşünen, endişe duyan ve kayg1 içinde bulunan insanların psikolojik olarak sağlıklı kalmaları da zorlaşmaktadır.

Dünya Sağlık Örgütü (World Health Organization-WHO), obezite sinıflandırmasında vücut kütle indeksi temel alınmaktadır. Vücut kütle indeksi, kişinin vücut ağırlı̆̆ının (kg) boy uzunluğunun (m) karesine bölünmesi (Vücut kütle indeksi: $\mathrm{kg} / \mathrm{m}^{2}$ ) ile ulaşılan bir değerdir. En uygun sağlı̆ga ulaşılması için beden gelişimini tamamlamış nüfusun ortalama vücut kütle indeksinin 21 ile 23 $\mathrm{kg} / \mathrm{m}^{2}$ aralı̆ğnda olması gerekmektedir (WHO, 2019).

Dünya Sağlık Örgütü’nün obezite sınıflandırllmasına göre;

- $<18.5 \mathrm{~kg} / \mathrm{m}^{2} \quad=$ Zayif

- $18.5-24.9 \mathrm{~kg} / \mathrm{m}^{2}=$ Normal Kilolu

- $25-29.9 \mathrm{~kg} / \mathrm{m}^{2}=$ Fazla Kilolu

- $\quad 30-34.9 \mathrm{~kg} / \mathrm{m}^{2}=$ Hafif Düzey Obez

- $\quad 35-39.9 \mathrm{~kg} / \mathrm{m}^{2}=$ Orta Düzey Obez

- $\geq 40 \mathrm{~kg} / \mathrm{m}^{2} \quad=$ İleri Düzey Obez olarak kabul edilmektedir (WHO, 2019).

Lise son sınıf öğrencileri üniversite sınavına hazırlandıkları bu süreç boyunca zamanlarının büyük bir kısmını ders çalışarak geçirmektedir. Öğrenciler tamamen sınava yoğunlaştıkları bu dönemde sosyal aktivitelerini en aza indirgeyip günün çoğunluğunda masa başında oturup hareketsiz kalmaktadırlar. Aynı zamanda sınav stresi yaşadıklanı ve her şeyden vakit kazanmaya çalıştıkları düşünüldügünde beslenme düzenleri bozulabilmektedir. Çalışma için özel öğretim kurumlarının seçilmesinin sebebi, bu kurumların eskiden bildiğimiz dershane sistemini devam ettiriyor olması ve normal liselerden farklı olarak hafta sonları da öğrenciler için çalışmalar yapıyor olmasıdır. Seçilen grubun lise son sınıf öğrencisi olasının nedeni ise, uzun soluklu ve yoğun sınav hazırlığından dolayı genellikle istemsizce kilo alınabilecek ya da verilebilecek bir dönem olmasıdır.

Bu çalışmada, öğrencilerin sosyal fizik kaygı düzeyinin cinsiyeti vücut kütle indeksi, spor yapma durumu, haftalık spor yapma günü ve fast-food yeme sıklı̆̆ına göre farkl1lı gösterip göstermediğinin tespit edilmesi amaçlanmıştır.

\section{Yöntem}

\subsection{Araştırma Modeli}

$\mathrm{Bu}$ çalışma, üniversite giriş sınavına hazırlanan öğrencilerin sosyal fizik kaygı düzeyinin belirlenmesi ve değişkenler açısından incelenmesi genel tarama modeli bağlamında ele alınmıştır.

\subsection{Araştırma Grubu}

Çalışmaya, 2018-2019 eğitim-öğretim yllında Aydın ili Efeler ilçesinde Milli Eğitim Müdürlüğü'ne bağlı üniversite giriş sınavlarına hazırlayan özel öğretim kurumlarında, lise son sınıf düzeyinde öğrenim gören, basit rastgele örnekleme yöntemi ile ulaşılmış 401 ( $n=216$ kadın, n=185 erkek) öğrenci gönüllü olarak katılmıştır. Katılımcıların değisskenlere göre frekans ve yüzdeleri Tablo 1 'de verilmektedir. 
Emiroğlu, D., \& Özmaden, M. (2020). Üniversite giriş sınavına hazırlanan öğrencilerin sosyal fizik kayg1 düzeyinin incelenmesi. Journal of Human Sciences, 17(4), 1034-1046. doi:10.14687/ihs.v17i4.6046

Tablo 1. Katılımcıların Değişkenlere Göre Frekans ve Yüzdesi (N=401)

\begin{tabular}{|c|c|c|c|}
\hline & & Frekans & Yüzde (\%) \\
\hline \multirow{2}{*}{ Cinsiyet } & Kadın & 216 & 53.9 \\
\hline & Erkek & 185 & 46.1 \\
\hline \multirow{4}{*}{ Vücut Kütle İndeksi } & Zayif & 61 & 15.2 \\
\hline & Normal Kilolu & 276 & 68.8 \\
\hline & Fazla Kilolu & 52 & 13 \\
\hline & Obez & 12 & 3 \\
\hline \multirow{2}{*}{ Spor Yapma Durumu } & Evet & 199 & 49.6 \\
\hline & Hayır & 202 & 50.4 \\
\hline \multirow{4}{*}{ Haftalık Spor Yapma Günü } & Hiç yapmam & 202 & 50.4 \\
\hline & 1-3 gün & 139 & 34.7 \\
\hline & 4-6 gün & 49 & 12.2 \\
\hline & Her gün & 11 & 2.7 \\
\hline \multirow{4}{*}{ Haftalık Fast-food Yeme Sıklığ1 } & Hiç yemem & 32 & 8 \\
\hline & 1-3 gün & 198 & 49.4 \\
\hline & 4-6 gün & 115 & 28.7 \\
\hline & Her gün & 56 & 14 \\
\hline
\end{tabular}

\subsection{Veri Toplama Araçları}

Kişisel Bilgi Formu: Çalışmaya katılan kişilerin cinsiyet, boy, kilo, spor yapma durumu, haftalık spor yapma günü, fast-food yeme sıklığı bilgilerini belirlemeye yönelik 6 sorudan oluşan formdur.

Sosyal Fizik Kaygı Envanteri: Hart ve ark. (1989) tarafindan geliştirilen ve Ballı ve Aşçı (2006) tarafindan Türkçeye uyarlanan sosyal fizik kayg1 envanteri, fiziksel görünüm rahatlı̆ı (FGR) (5 madde) ve olumsuz değerlendirilme beklentisi (ODB) (7 madde) olmak üzere iki alt boyutlu olup toplam 12 maddeden oluşmaktadır. Maddeler 5'li derecelendirme sistemine göre hazırlanmış olup "Tamamen doğru (5), Genellikle doğru (4), Bazen doğru bazen yanlış (3), Genellikle yanlış (2), Tamamen yanlış (1)" şeklinde derecelendirilmiştir.

İç tutarlık katsayısı, FGR alt boyutu için kadınlarda 0.77, erkeklerde 0.75; ODB alt boyutu için kadınlarda 0.69, erkeklerde 0.68; tüm envanter için kadınlarda 0.81, erkeklerde 0.77 olarak bulunmuştur. Test-Tekrar Test korelasyon katsayısı, kadınlarda her iki alt boyut için 0.80 , erkeklerde FGR alt boyutu için 0.76 ve ODB alt boyutu için 0.77 ; tüm envanter için kadınlarda 0.88 , erkeklerde 0.81 bulunmuştur.

Envanterdeki 1., 2., 5., 8. ve 11. maddeler ters puanlanmaktadır. Envanterden alınacak en düşük puan 12, en yüksek puan 60’tır. Envanterden alınan puan arttıkça kişinin sosyal fizik kayg1 (SFK) düzeyi de artmaktadır (Ballı ve Aşçı, 2006).

Ölçek dereceleri $0.80(5-1=4 ; 4 / 5=0.80)$ oranında eşit aralıklara bölündüğünde, 1.00-1.80 Çok Düşük Düzey, 1.81-2.60 Düşük Düzey, 2.61-3.40 Orta Düzey, 3.41-4.20 Yüksek Düzey, 4.21-5.00 Çok Yüksek Düzey şeklinde belirlenmiştir (Özmaden ve Yıldıran, 2003).

Kattlımcıların sosyal fizik kayg1 ve alt boyutlarına ilişkin frekans ve yüzdesi Tablo 2'de verilmektedir.

Tablo 2. Katılımcıların SFK ve Alt Boyutları Ortalamalarının Frekans ve Yüzdesi (N=401).

\begin{tabular}{lcccccc}
\hline & \multicolumn{2}{c}{ Sosyal Fizik Kaygı } & $\begin{array}{c}\text { Olumsuz Değerlendirilme } \\
\text { Beklentisi }\end{array}$ & \multicolumn{2}{c}{ Fiziksel Görünüm Rahatlı̆̆ı } \\
& Frekans & Yüzde & Frekans & Yüzde & Frekans & Yüzde \\
\hline Çok Düşük & 29 & 7.1 & 68 & 16.9 & 20 & 4.9 \\
\hline Düşük & 166 & 41.3 & 160 & 39.9 & 74 & 18.4 \\
\hline Orta & 154 & 38.2 & 109 & 27.2 & 164 & 40.9 \\
\hline Yüksek & 49 & 12.1 & 62 & 15.4 & 102 & 25.4 \\
\hline Çok Yüksek & 3 & 0.6 & 2 & 0.4 & 41 & 10.2 \\
\hline
\end{tabular}


Emiroğlu, D., \& Özmaden, M. (2020). Üniversite giriş sınavına hazırlanan öğrencilerin sosyal fizik kayg1 düzeyinin incelenmesi. Journal of Human Sciences, 17(4), 1034-1046. doi:10.14687/ihs.v17i4.6046

\subsection{Verilerin Toplanmas1}

Verilerin toplanmasına başlamadan önce belirlenen okullara gidilerek, rehberlik öğretmenleri ile çalışma ile ilgili görüşme yapılmıştır. Ölçeğin uygulanacağı sınıfların uygun zaman bilgileri alınarak her sınıfa belirlenen saatlerde ölçek uygulaması için gidilmiştir. Araştırmacı tarafindan ölçekler dağıtılmış, çalışmaya katılan öğrencilere çalışmanın önemi ve bireylerin bu çalışma için taşıdığ1 önem hakkında bilgiler verilmiştir. Bu kapsamda öğrencilere, doğru ve samimi cevaplar vermelerinin çalışmanın güvenirliğini etkileyeceği açıklanmıştır. Ölçeklerin cevaplandırılma süresi yaklaşık 10-15 dakika sürmüştür. Dağıtılan 500 ölçeğin 99 tanesi öğrenciler tarafindan hatalı ve eksik doldurulduğu için değerlendirmeye alınmamış ve sonuç olarak 401 ölçek geçerli olarak kabul edilmiş ve değerlendirmeye alınmıştır.

\subsection{Verilerin Analizi}

Çalışmada araştırma bulguları, katılımcılardan elde edilen veriler üzerinde Statistical Package for Social Sciences (SPSS) 22.00 paket programı kullanılarak gerçekleştirilen analizlerin sonucunda elde edilmiştir. Ölçek ve alt boyutlanına ait normal dağılım analizi sonuçları Tablo 3'de verilmektedir.

Tablo 3. Normal Dağılım Analizi Sonuçları

\begin{tabular}{cccccc}
\hline & $\mathbf{N}$ & $\overline{\mathbf{X}}$ & Ss & Skewness & \multicolumn{2}{c}{ Kurtosis } \\
\hline Sosyal Fizik Kayg1 & 401 & 2.68 & .61 & .26 & -.37 \\
\hline Olumsuz Değerlendirilme Beklentisi & 401 & 2.55 & .73 & .29 & -.62 \\
\hline Fiziksel Görünüm Rahatlı̆̆1 & 401 & 3.25 & .81 & -.04 & -.26 \\
\hline
\end{tabular}

Ölçek ve alt boyutlarına ait dağılımın normalliği Skewness ve Kurtosis değerleri incelenerek ortaya konulmuştur. Skewness değerlerinin -1 ile +1 , Kurtosis değerlerinin -3 ile +3 aralığında olması dağılımın normal olduğunu göstermektedir.

Tablo 3'e bakıldığında, Skewness ve Kurtosis değerlerinin normal dağglım aralığında olduğu görülmektedir. Bu nedenle analizler sırasında parametrik teknikler kullanılmıştır.

Öğrencilerin SFK, ODB alt boyut ve FGR alt boyut düzeylerinin cinsiyet ve spor yapma durumu açısından karşılaştırılması için Bağımsız Gruplarda t Testi uygulanmıştır.

Öğrencilerin SFK, ODB alt boyut ve FGR alt boyut düzeylerinin vücut kütle indeksi, haftalık spor yapma günü ve haftalık fast-food yeme sıklı̆̆ bakımından farklı olup olmadığını test etmek amacıyla Tek Yönlü Varyans Analizi (One Way ANOVA) yapılmışır. Farklılı̆̆n hangi gruplardan kaynaklandığını tespit edebilmek için Post Hoc testlerinden Hochberg's GT2 testi uygulanmıştır.

Tek yönlü varyans analizi testi yapabilmek için varyansların homojen olup olmadığı Levene Testi ile kontrol edilerek analizler yapılmıstır. Tüm analizler için anlamlılık düzeyi 0.05 olarak alınmıştır.

\section{Bulgular}

$\mathrm{Bu}$ bölümde, öğrencilerin sosyal fizik kayg1 ve alt boyutları düzeylerine ilişkin değişkenler açısından yapılan analizlerin bulgularına yer verilmiştir. 
Emiroğlu, D., \& Özmaden, M. (2020). Üniversite giriş sınavına hazırlanan öğrencilerin sosyal fizik kayg1 düzeyinin incelenmesi. Journal of Human Sciences, 17(4), 1034-1046. doi:10.14687/ihs.v17i4.6046

Tablo 4. Katılımcıların SFK ve Alt Boyutları Puanlarının Cinsiyete Göre Tanımlayıcı Değerleri ve Bağımsız Gruplarda T Testi Sonuçları

\begin{tabular}{|c|c|c|c|c|c|c|c|}
\hline & & $\mathbf{N}$ & $\overline{\mathbf{X}}$ & Ss & $\mathbf{F}$ & $\mathbf{t}$ & $\mathrm{p}$ \\
\hline \multirow{2}{*}{ Sosyal Fizik Kayg1 } & Kadın & 216 & 2.82 & .61 & \multirow{2}{*}{.68} & \multirow{2}{*}{5.28} & \multirow{2}{*}{$.00 *$} \\
\hline & Erkek & 185 & 2.51 & .56 & & & \\
\hline \multirow{2}{*}{ Olumsuz Değerlendirilme Beklentisi } & Kadin & 216 & 2.70 & .75 & \multirow{2}{*}{2.36} & \multirow{2}{*}{4.38} & \multirow{2}{*}{$.00 *$} \\
\hline & Erkek & 185 & 2.38 & .67 & & & \\
\hline \multirow{2}{*}{ Fiziksel Görünüm Rahatlığ1 } & Kadin & 216 & 3.03 & .78 & \multirow{2}{*}{.01} & \multirow{2}{*}{-6.18} & \multirow{2}{*}{$.00 *$} \\
\hline & Erkek & 185 & 3.51 & .77 & & & \\
\hline
\end{tabular}

$* \mathrm{p}<0.05$

Tablo 4 incelendiğinde, kadınların SFK $(\overline{\mathrm{X}}=2.82)$, ODB alt boyut $(\overline{\mathrm{X}}=2.70)$ ve FGR alt boyut $(\overline{\mathrm{X}}=3.03)$ puanlarının orta düzeyde olduğu tespit edilmiştir. Erkeklerin SFK $(\overline{\mathrm{X}}=2.51)$ ve ODB alt boyut $(\overline{\mathrm{X}}=2.38)$ puanlanının düşük düzeyde olduğu, FGR alt boyut puanının $(\overline{\mathrm{X}}=3.51)$ ise yüksek olduğu görülmektedir.

Kadınların ve erkeklerin SFK düzeyleri, ODB ve FGR alt boyut puanları arasinda istatistiksel olarak anlamlı farll11k bulunmuştur $(\mathrm{p}<0.05)$.

Kadınların SFK ortalamasının ( $\overline{\mathrm{X}}=2.82)$ erkeklerin ortalamasına göre $(\overline{\mathrm{X}}=2.51)$ daha yüksek olduğu görülmektedir. Ayrıca kadınların ODB alt boyut ortalaması da $(\overline{\mathrm{X}}=2.70)$ erkeklerin ortalamasından ( $\overline{\mathrm{X}}=2.38)$ yüksek çıkmıştır. FGR alt boyut puanında ise kadınların ortalamasının $(\overline{\mathrm{X}}=3.03)$ erkeklerden $(\overline{\mathrm{X}}=3.51)$ düşük olduğu görülmektedir.

Tablo 5. Katılımcıların SFK ve Alt Boyutları Puanlarına İlişkin Vücut Kütle İndeksine Göre Tanımlayıcı Değerleri ve Tek Yönlü Varyans Analizi Sonuçları

\begin{tabular}{|c|c|c|c|c|c|c|}
\hline & & $\mathbf{N}$ & $\overline{\mathbf{X}}$ & Ss & F & $\mathrm{p}$ \\
\hline \multirow{4}{*}{ Sosyal Fizik Kayg1 } & Zayif & 61 & 2.69 & .56 & \multirow{4}{*}{2.45} & \multirow{4}{*}{.06} \\
\hline & Normal Kilolu & 276 & 2.64 & .59 & & \\
\hline & Fazla Kilolu & 52 & 2.89 & .68 & & \\
\hline & Obez & 12 & 2.62 & .63 & & \\
\hline \multirow{4}{*}{$\begin{array}{c}\text { Olumsuz } \\
\text { Değerlendirilme } \\
\text { Beklentisi }\end{array}$} & Zayıf & 61 & 2.53 & .64 & \multirow{4}{*}{2.59} & \multirow{4}{*}{.05} \\
\hline & Normal Kilolu & 276 & 2.52 & .72 & & \\
\hline & Fazla Kilolu & 52 & 2.81 & .83 & & \\
\hline & Obez & 12 & 2.40 & .75 & & \\
\hline \multirow{4}{*}{$\begin{array}{c}\text { Fiziksel Görünüm } \\
\text { Rahatlığı }\end{array}$} & Zayif & 61 & 3.34 & .70 & \multirow{4}{*}{3.15} & \multirow{4}{*}{$.02 *$} \\
\hline & Normal Kilolu & 276 & 3.30 & .81 & & \\
\hline & Fazla Kilolu & 52 & 2.94 & .86 & & \\
\hline & Obez & 12 & 3.16 & .92 & & \\
\hline
\end{tabular}

$* \mathrm{p}<0.05$

Tablo 5'te, zayıf grubundaki öğrencilerin SFK $(\bar{X}=2.69)$ ve FGR alt boyut $(\bar{X}=3.34)$ puanlarının orta düzeyde olduğu görülürken, ODB alt boyut puanının $(\bar{X}=2.53)$ düşük düzeyde olduğu görülmektedir. Normal kilolu grubunda yer alan öğrencilerin de SFK ( $\bar{X}=2.64)$ ve FGR alt boyut $(\overline{\mathrm{X}}=3.30)$ puanları orta düzeydeyken, ODB alt boyut puanının $(\overline{\mathrm{X}}=2.52)$ düşük düzeyde olduğu görülmektedir. Fazla kilolu grubundaki öğrencilerin SFK ( $\bar{X}=2.89)$, ODB alt boyut $\overline{\mathrm{X}}=2.81)$ ve FGR alt boyut $(\overline{\mathrm{X}}=2.94)$ düzeylerinin her birinde orta düzeyde olduğu belirlenmiştir. Obez grubundaki öğrencilerin ise, SFK $(\bar{X}=2.62)$ ve FGR alt boyut $(\bar{X}=3.16)$ puanları orta düzeydeyken, $\mathrm{ODB}$ alt boyut puanının $(\overline{\mathrm{X}}=2.40)$ düşük düzeyde olduğu tespit edilmiştir.

Varyansların homojen dağılımını tespit etmek için uygulanan Levene testinde " $\mathrm{p}$ " değeri 0.05 ’ten büyük ise varyans eşitliğinin sağlandığı kabul edilir. Katulımcıların SFK'ya ilişkin 
Emiroğlu, D., \& Özmaden, M. (2020). Üniversite giriş sınavına hazırlanan öğrencilerin sosyal fizik kayg1 düzeyinin incelenmesi. Journal of Human Sciences, 17(4), 1034-1046. doi:10.14687/ihs.v17i4.6046

varyanslarının $[\mathrm{F}(3.397)=.94, \mathrm{p}=.41], \mathrm{ODB}$ alt boyutuna ilişkin varyanslarının $[\mathrm{F}(3.397)=1.69$, $\mathrm{p}=.16]$ ve FGR alt boyutuna ilisskin varyanslarının $[\mathrm{F}(3.397)=.86, \mathrm{p}=.46]$ homojen olduğu belirlenmiştir.

Tablo 5'te vücut kütle indeksine göre SFK ve ODB alt boyut ortalamalarında anlamlı bir fark olmadığı görülmektedir ( $\mathrm{p}>0.05)$. Ancak FGR alt boyut ortalamasında gruplar arasında anlamlı düzeyde farkllilı olduğu görülmektedir $(\mathrm{p}<0.05)$.

Farkın hangi gruptan kaynaklandığını tespit etmek için Post Hoc testlerinden Hochberg's GT2 testi uygulanmıştır. Hochberg testi sonuçlarına göre, normal kiloluların FGR alt boyut ortalaması $(\overline{\mathrm{X}}=3.30)$ fazla kiloluların ortalamasından $(\overline{\mathrm{X}}=2.94)$ daha yüksektir.

Tablo 6. Katılımcıların SFK ve Alt Boyutları Puanlarının Spor Yapma Durumuna Göre Tanımlayıcı Değerleri ve Bağımsız Gruplarda T Testi Sonuçları

\begin{tabular}{|c|c|c|c|c|c|c|c|}
\hline & & $\mathbf{N}$ & $\overline{\mathbf{X}}$ & Ss & $\mathbf{F}$ & $\mathbf{t}$ & $\mathrm{p}$ \\
\hline \multirow{2}{*}{ Sosyal Fizik Kayg1 } & Evet & 199 & 2.5 & .58 & \multirow{2}{*}{.03} & \multirow{2}{*}{-5.96} & \multirow{2}{*}{$.00 *$} \\
\hline & Hayır & 202 & 2.85 & .59 & & & \\
\hline \multirow{2}{*}{ Olumsuz Değerlendirilme Beklentisi } & Evet & 199 & 2.39 & .70 & \multirow{2}{*}{.51} & \multirow{2}{*}{-4.5} & \multirow{2}{*}{$.00 *$} \\
\hline & Hayır & 202 & 2.71 & .72 & & & \\
\hline \multirow{2}{*}{ Fiziksel Görünüm Rahatlığ1 } & Evet & 199 & 3.52 & .78 & \multirow{2}{*}{.53} & \multirow{2}{*}{6.22} & \multirow{2}{*}{$.00 *$} \\
\hline & Hayır & 202 & 2.99 & .76 & & & \\
\hline
\end{tabular}

$* \mathrm{p}<0.05$

Tablo 6'da, spor yapan öğrencilerin SFK $(\overline{\mathrm{X}}=2.5)$ ve ODB alt boyut $(\overline{\mathrm{X}}=2.39)$ puanlar1 düşük düzeyde, FGR alt boyut $(\overline{\mathrm{X}}=3.52)$ puanı yüksek düzeydedir. Spor yapmayan öğrencilerin ise SFK $(\bar{X}=2.85)$, ODB alt boyut $(\bar{X}=2.71)$ ve FGR alt boyut $(\bar{X}=2.99)$ puanlanının orta düzeyde olduğu görülmektedir.

Spor yapma durumuna göre SFK, ODB alt boyut ve FGR alt boyut ortalamalarında anlamlı düzeyde fark olduğu görülmektedir $(\mathrm{p}<0.05)$.

Spor yapmayan öğrencilerin SFK ortalaması $(\bar{X}=2.85)$ spor yapan öğrencilerinden $(\bar{X}=2.5)$ daha yüksek çıkmıştır. Spor yapmayan ögrencilerin ODB alt boyut ortalamasının $(\bar{X}=2.71)$ da spor yapanlara göre $(\bar{X}=2.39)$ yüksek olduğu görülmektedir. Bu sonuçların yanı sıra FGR alt boyut ortalaması spor yapmayanların $(\overline{\mathrm{X}}=2.99)$ spor yapanlardan $(\overline{\mathrm{X}}=3.52)$ daha düşük olduğu görülmektedir.

Tablo 7. Katılımcıların SFK ve Alt Boyutları Puanlarına İlişkin Haftalık Spor Yapma Gününe Göre Tanımlayıcı Değerleri ve Tek Yönlü Varyans Analizi Sonuçları

\begin{tabular}{|c|c|c|c|c|c|c|}
\hline & & $\mathbf{N}$ & $\overline{\mathbf{X}}$ & Ss & $\mathbf{F}$ & $\mathrm{p}$ \\
\hline \multirow{4}{*}{ Sosyal Fizik Kayg1 } & Hiç yapmam & 202 & 2.85 & .59 & \multirow{4}{*}{12.55} & \multirow{4}{*}{$.00 *$} \\
\hline & 1-3 gün & 139 & 2.52 & .57 & & \\
\hline & 4-6 gün & 49 & 2.52 & .60 & & \\
\hline & Her gün & 11 & 2.26 & .52 & & \\
\hline \multirow{4}{*}{$\begin{array}{c}\text { Olumsuz } \\
\text { Değerlendirilme } \\
\text { Beklentisi }\end{array}$} & Hiç yapmam & 202 & 2.71 & .72 & \multirow{4}{*}{7.51} & \multirow{4}{*}{$.00^{*}$} \\
\hline & 1-3 gün & 139 & 2.38 & .68 & & \\
\hline & 4-6 gün & 49 & 2.48 & .75 & & \\
\hline & Her gün & 11 & 2.14 & .60 & & \\
\hline \multirow{4}{*}{$\begin{array}{c}\text { Fiziksel Görünüm } \\
\text { Rahatlığ1 }\end{array}$} & Hiç yapmam & 202 & 2.99 & .76 & \multirow{4}{*}{16.51} & \multirow{4}{*}{$.00 *$} \\
\hline & 1-3 gün & 139 & 3.49 & .75 & & \\
\hline & 4-6 gün & 49 & 3.53 & .86 & & \\
\hline & Her gün & 11 & 3.85 & .71 & & \\
\hline
\end{tabular}

$* \mathrm{p}<0.05$ 
Emiroğlu, D., \& Özmaden, M. (2020). Üniversite giriş sınavına hazırlanan öğrencilerin sosyal fizik kayg1 düzeyinin incelenmesi. Journal of Human Sciences, 17(4), 1034-1046. doi:10.14687/ihs.v17i4.6046

Tablo 7’ye bakıldığında, hiç spor yapmayan öğrencilerin SFK (X $=2.85)$, ODB alt boyut $\overline{\mathrm{X}}=2.71)$ ve FGR alt boyut $(\overline{\mathrm{X}}=2.99)$ puanlarının orta düzeyde olduğu görülmektedir. Haftada 1-3 gün spor yapan öğrencilerin $\mathrm{SFK}(\overline{\mathrm{X}}=2.52)$ ve $\mathrm{ODB}$ alt boyut $(\overline{\mathrm{X}}=2.38)$ puanları düşük düzeyde ve FGR alt boyut $(\overline{\mathrm{X}}=3.49)$ puanı orta düzeydedir. Haftada 4-6 gün spor yapan öğrencilerin SFK $(\bar{X}=2.52)$ ve $\mathrm{ODB}$ alt boyut $(\overline{\mathrm{X}}=2.48)$ puanları düşük düzeyde, FGR alt boyut $(\overline{\mathrm{X}}=3.53)$ puanı ise yüksek düzeydedir. Her gün spor yapan öğrencilerin ortalamalarına bakıldığında ise SFK $(\bar{X}=2.26)$ ve ODB alt boyut $(\bar{X}=2.14)$ puanlarının düşük düzeyde olduğu, FGR alt boyut $(\bar{X}=3.85)$ puanının yüksek düzeyde olduğu görülmektedir.

Varyansların homojen dağılımını tespit etmek için uygulanan Levene testinde "p" değeri 0.05 'ten büyük ise varyans eşitliğinin sağlandığı kabul edilir. Katılımcıların SFK'ya ilişkin varyansları $[\mathrm{F}(3.397)=.16, \mathrm{p}=.92], \mathrm{ODB}$ alt boyutuna ilişkin varyansları $[\mathrm{F}(3.397)=.75, \mathrm{p}=.52]$ ve FGR alt boyutuna ilişkin varyanslanı $[\mathrm{F}(3.397)=.77, \mathrm{p}=.50]$ homojendir.

Tablo 7’ye incelendiğinde gruplar arasında anlamlı bir fark olduğu görülmektedir $(\mathrm{p}<0.05)$.

Farkın hangi gruptan kaynaklandığını tespit etmek için Post Hoc testlerinden Hochberg's GT2 testi uygulanmıştır. Hochberg testi sonuçlarına göre, hiç spor yapmayan öğrencilerin SFK ortalamas1 1-3 gün, 4-6 gün ve her gün spor yapan öğrencilerden daha yüksektir. En yüksek SFK düzeyi hiç spor yapmayan öğrencilerde görülürken $(\overline{\mathrm{X}}=2.85)$, en düşük SFK düzeyi her gün spor yapan öğrencilerde $(\overline{\mathrm{X}}=2.26)$ görülmüştür.

Bunun tam tersi sonuç olarak, hiç spor yapmayan öğrencilerin FGR alt boyut ortalaması 1-3 gün, 4-6 gün ve her gün spor yapan öğrencilerden daha düşüktür. En düşük FGR alt boyut düzeyi hiç spor yapmayan öğrencilerde görülürken $(\bar{X}=2.99)$, en yüksek FGR alt boyut düzeyi her gün spor yapan öğrencilerde $\overline{\mathrm{X}}=3.85)$ görülmüştür.

Ayrıca hiç spor yapmayan öğrencilerin ODB alt boyut ortalaması $(\bar{X}=2.71) 1-3$ gün spor yapan öğrencilerin ortalamasına $(\overline{\mathrm{X}}=2.38)$ göre daha yüksektir.

Tablo 8. Katılımcıların SFK ve Alt Boyutları Puanlarına İlişkin Haftalık Fast-Food Yeme Sıklığına Göre Tanımlayıcı Değerleri ve Tek Yönlü Varyans Analizi Sonuçları

\begin{tabular}{|c|c|c|c|c|c|c|}
\hline & & $\mathbf{N}$ & $\overline{\mathbf{X}}$ & Ss & $\mathbf{F}$ & $\mathrm{p}$ \\
\hline \multirow{4}{*}{ Sosyal Fizik Kayg1 } & Hiç yemem & 32 & 2.60 & .62 & \multirow{4}{*}{.33} & \multirow{4}{*}{.79} \\
\hline & 1-3 gün & 198 & 2.71 & .62 & & \\
\hline & 4-6 gün & 115 & 2.66 & .61 & & \\
\hline & Her gün & 56 & 2.67 & .56 & & \\
\hline \multirow{4}{*}{$\begin{array}{l}\text { Olumsuz Değerlendirilme } \\
\text { Beklentisi }\end{array}$} & Hiç yemem & 32 & 2.44 & .77 & \multirow{4}{*}{.51} & \multirow{4}{*}{.67} \\
\hline & 1-3 gün & 198 & 2.58 & .76 & & \\
\hline & 4-6 gün & 115 & 2.52 & .67 & & \\
\hline & Her gün & 56 & 2.59 & .70 & & \\
\hline \multirow{4}{*}{$\begin{array}{l}\text { Fiziksel Görünüm } \\
\text { Rahatlığ1 }\end{array}$} & Hiç yemem & 32 & 3.26 & .69 & \multirow{4}{*}{.48} & \multirow{4}{*}{.69} \\
\hline & 1-3 gün & 198 & 3.21 & .84 & & \\
\hline & 4-6 gün & 115 & 3.29 & .81 & & \\
\hline & Her gün & 56 & 3.33 & .79 & & \\
\hline
\end{tabular}

Tablo 8'de, hiç fast-food tüketmeyen öğrencilerin SFK $(\bar{X}=2.60)$ ve ODB alt boyut $(\bar{X}=2.44)$ puanları düşük düzeydeyken, FGR alt boyut $(\bar{X}=3.26)$ puanı orta düzeydedir. Haftada 1-3 gün fast-food yiyen ögrrencilerin $\mathrm{SFK}(\overline{\mathrm{X}}=2.71)$ ve $\mathrm{FGR}$ alt boyut $(\overline{\mathrm{X}}=3.21)$ puanları orta düzeyde, ODB alt boyut $(\bar{X}=2.58)$ puanı ise düşük düzeyde çıkmıştır. Haftanın 4-6 günü fast-food tüketen öğrencilerin SFK ( $\overline{\mathrm{X}}=2.66)$ ve FGR alt boyut $(\overline{\mathrm{X}}=3.29)$ puanları orta düzeyde, ODB alt boyut $\overline{\mathrm{X}}=2.52)$ puanı ise düşük düzeyde bulunmuştur. Her gün fast-food yiyen öğrencilerin ise SFK 
Emiroğlu, D., \& Özmaden, M. (2020). Üniversite giriş sınavına hazırlanan öğrencilerin sosyal fizik kayg1 düzeyinin incelenmesi. Journal of Human Sciences, 17(4), 1034-1046. doi:10.14687/ihs.v17i4.6046

$(\overline{\mathrm{X}}=2.67)$ ve FGR alt boyut $(\overline{\mathrm{X}}=3.33)$ puanlarının orta düzeyde, ODB alt boyut $(\overline{\mathrm{X}}=2.59)$ puanının ise düşük düzeyde olduğu görülmektedir.

Varyansların homojen dağılımını tespit etmek için Levene testi uygulanmıştır. Levene testinde " $p$ " değeri 0.05 'ten büyük ise varyans eşitliğinin sağlandığı kabul edilir. Katılımcıların SFK'ya ilişkin puan varyanslarının [F $(3.397)=.26, \mathrm{p}=.85]$, ODB alt boyutuna ilişkin varyanslarının $[\mathrm{F}(3.397)=1.31, \mathrm{p}=.26]$ ve $\mathrm{FGR}$ alt boyutuna ilişkin varyanslarının $[\mathrm{F}(3.397)=.39, \mathrm{p}=.75]$ homojen olduğu belirlenmiştir.

Tablo 8'de gruplar arasında, haftalık fast-food yeme sıklı̆ına göre SFK düzeyinde, ODB ve FGR alt boyutunda anlamlı bir farkllığın olmadığı görülmektedir ( $\mathrm{p}>0.05)$.

\section{Tartışma ve Sonuç}

Öğrencilerin cinsiyete ilişkin SFK, ODB alt boyut ve FGR alt boyut düzeyleri arasında anlamlı farklılıklar olduğu görülmektedir. Kadın öğrencilerin SFK ve ODB alt boyut düzeylerinin erkek öğrencilerden daha yüksek olduğu tespit edilmiştir. Fakat öğrencilerin FGR alt boyut düzeyine bakıldığında erkeklerin ortalamasının kadınlara göre daha yüksek olduğu görülmektedir.

İnsanlar, fiziğinin ön planda olduğu etkinliklere katılması gerektiğinde ya da başka insanlar tarafindan incelendiği durumlarda rezil olacağı, utanacağı ve utancının diğer insanlar tarafindan fark edileceği konusunda endişe yaşamaktadır. Lise öğrencileri, içinde bulundukları ergenlik dönemi nedeniyle diğer yaş gruplarına göre dış görünüşü hakkında daha endişelidir. Ergenlik dönemindeki ergenlerin, hızlı fiziksel gelişime uyum sağlamaya çalışması ve bu değişiklikler ile başa çıkma çabasında olması sebebiyle en büyük uğraşları bedenleridir. Kızlar hızlı büyüme ve cinsel gelişimi erkeklerden daha önce yaşar. Bu büyüme ve gelişim erkeklerin ruh sağlığını genellikle olumlu etkilemesine rağmen kızlarda daha düşük benlik saygısına, daha yüksek depresyon oranına, anksiyete ve yeme bozukluklarına sebep olmaktadır (Derman, 2008,). Kadın öğrencilerin SFK ve ODB alt boyut düzeylerinin erkeklerden daha yüksek olması, ergenlik döneminden kaynaklanan fiziksel değişimleri daha belirgin şekilde yaşamalarından kaynaklanıyor olabilir.

Arabacı (2008), Chu ve ark. (2008), Pekdağ ve Çoşkun (2010), Ersöz (2011), Yaşartürk ve ark. (2014), McLester ve ark. (2018)'nın üniversite öğrencilerini kapsayan SFK ile ilgili çalışmalar ile Eren (2012) ve Şahin'in (2018) spor salonuna giden yetişkinlerin SFK düzeyini araştırdığı çalışmaları incelendiğinde, kadınların erkeklere göre fiziksel görünüşünden daha çok rahatsızlık duyduğu bulgularının olması çalışmayı destekler niteliktedir.

Sarıkabak ve ark. (2019)'nın lise öğrencilerinin SFK durumunu incelendiği çalışmada, kız öğrencilerin SFK durumu erkek öğrencilerden daha yüksektir ve bu durum çalışma ile hem yaş grubu hem de sonuç bakımından benzerlik göstermektedir.

Öğrencilerin vücut kütle indeksi hesaplanarak elde edilen verilere ilişkin SFK, ODB alt boyut ve FGR alt boyut düzeylerinde anlamlı farklliklar olduğu görülmektedir. Bu farklilikların belirlenmesi için uygulanan Hochberg testi sonuçlarına göre, normal kilolu grubunda yer alan öğrencilerin FGR alt boyut ortalamasının fazla kilolu grubundaki öğrencilerden daha yüksek olduğu sonucuna varilmıştır.

Normal kilolu grubunda yer alan öğrencilerin fazla kilo aralığında olan öğrencilerden fiziksel görünümleri ile ilgili daha rahat olma nedeni, dışarıdan bakıldığında genel olarak betimlenmiş olan fizik algisına normal kilolu bireylerin fazla kilolu bireylerden daha yakın oldukları düşünülebilir. $\mathrm{Bu}$ nedenle normal kilo aralığında olan öğrencilerin fizikleri konusunda daha rahat ve özgüvenli olabilecekleri söylenebilir.

Arabac1 (2008), üniversite öğrencilerinin SFK's1 ile vücut kompozisyonu arasındaki ilişkiyi araştırmış ve SFK durumu ile vücut kütle indeksi arasında anlamlı düzeyde bir ilişki olmadığını belirtmiştir.

Aston (2018) yapmış olduğu çalısmada, yüksek vücut kitle indeksinin yüksek sosyal fizik kayg1 seviyesi ile pozitif ilişkisini saptamış fakat vücut kütle indeksi ile sosyal fizik kaygı arasındaki ilişkinin anlamlı olmadığını bulmuştur. 
Emiroğlu, D., \& Özmaden, M. (2020). Üniversite giriş sınavına hazırlanan öğrencilerin sosyal fizik kayg1 düzeyinin incelenmesi. Journal of Human Sciences, 17(4), 1034-1046. doi:10.14687/ihs.v17i4.6046

McLester ve ark. (2018) ise, düşük vücut kütle indeksine sahip öğrencilerin vücut memnuniyetlerinin daha yüksek olduğunu belirtmiştir. $\mathrm{Bu}$ durumda, öğrencilerin vücut memnuniyetinin yüksek olması sosyal fizik kaygıyı daha az yaşadıkları ile bağdaştırılabilir.

Katılımcıların spor yapma durumları açısından SFK, ODB alt boyut ve FGR alt boyut düzeylerinde istatistiksel olarak anlamlı farkll1ıklar görülmüştür. Spor yapmayan öğrencilerin SFK ve ODB alt boyut düzeyleri spor yapan öğrencilerden yüksek olmasina rağmen, FGR alt boyut düzeyine bakıldığında spor yapan öğrencilerin spor yapmayan öğrencilere göre daha yüksek ortalamaya sahip olduğu görülmektedir.

İnsanların sağlıklı yaşam için spor yapmasının yanı sıra fiziklerinin daha iyi görünmesini sağlamak için de spor yaptığı göz ardı edilemez bir durumdur. Bu nedenle, spor yapmayan ögrenciler sosyal fizik ve olumsuz değerlendirilme kaygısını daha yoğun yaşarken, spor yapan öğrencilerin fiziksel görünümünden daha memnun ve rahat olduğu yorumu yapılabilir.

Çalışma sonuçlarına benzer olarak, Ballı ve ark. (2006)'nın yapmış olduğu araştırmada, spor yapmayan bayanların SFK düzeyinin spor yapan bayanlara göre daha yüksek olduğu belirtilmiştir. Benzer şekilde Bartlewski (1996), bir dönem boyunca aerobik egzersiz yapan kadınların sosyal fizik kaygısının azaldığını tespit etmiştir.

Sarıkabak ve ark. (2019)'nın çalışma bulguları, bu araştırmanın sonuçları ile benzerlik gösterir nitelikte olup, spor yapan lise öğrencilerinin SFK düzeyi ve ODB alt boyut puanının spor yapmayan öğrencilerden daha düşük olduğunu göstermektedir.

Bu çalışmadan farklı olarak, Sucu'nun (2018) yapmış olduğu araştrrmada öğrencilerin spor yapma durumuna göre SFK düzeyinin farklılık göstermediği sonucuna ulaşmıştır.

Haftalık spor yapma gününe göre gruplandırılan öğrencilerin SFK, ODB alt boyut ve FGR alt boyut düzeylerinde istatistiksel olarak anlamlı farklılıklar görülmüştür. Spor yapmayan öğrencilerin SFK ve ODB alt boyut düzeyleri, 1-3 gün, 4-6 gün ve her gün spor yapan öğrencilerden daha yüksek bulunmuştur. En yüksek kayg1 puanı spor yapmayan gruptaki öğrencilerde görülürken, en düşük kayg1 puanı her gün spor yapan grupta yer alan öğrencilerde görülmektedir. FGR alt boyut ortalamaları göz önüne alındığında, spor yapmayan öğrencilerin 1-3 gün, 4-6 gün ve her gün spor yapanlara göre daha düşük ortalamada olduğu görülmüştür. En düşük ortalama spor yapmayan öğrencilerde, en yüksek ortalama ise her gün spor yapan öğrencilerde görülmektedir.

Spor yapan ve yapmayan ögrrencilerin SFK, ODB alt boyut ve FGR alt boyut düzeylerinde fark olduğu düşünüldüğ̈̈nde; spor yapan öğrencilerin haftalık spor yapma gününe göre farlılıkların görülmesi beklenen bir durumdur. Bireyin ne kadar sık spor yaparsa kayg1 düzeyinin o kadar düşebileceği ve fiziksel görünümünden bir o kadar daha rahat olacağı söylenebilir.

Haftalık fast-food yeme sıklı̆̆ı göz önüne alındığında, öğrencilerin SFK düzeyinde, ODB ve FGR alt boyutlarında anlamlı bir farklılığın olmadığı görülmektedir.

Çalışmada, öğrenciler fast-food yeme sikllğına göre değerlendirildiğinde en az fast-food tüketen öğrencilerin SFK düzeyinin fazla tüketen öğrencilere göre daha yüksek olabileceği düşünülmüştür. Çalışma sonuçlarına göre, öğrencilerin SFK düzeyinin fast-food yeme sıkllğına göre farklı olmadığ1 görülmüştür. Bu durum, öğrencilerin günün büyük bir kısmını okulda geçirdiği düşünüldügün̈de ve okulda en hızlı ve kolay ulaşabilecekleri yiyeceklerin genellikle fast-food olduğu için bu tarz beslenmeyi istemeden de olsa kabullenmiş olabilecekleri şeklinde açılanabilir.

Spor, eğitimin ayrılmaz bir parçası olarak kabul edilerek önemli katkılar sağlayan, öğrencilerin fiziksel, psikolojik ve kişilik gelişimine destek olan, karşılıklı dayanışmayı öğreten, özgüveni geliştiren, başkalarına sayg1 göstermeyi aşılayan önemli bir faaliyettir (Soyer ve ark., 2010). Fiziksel aktiviteler reklamlar, sosyal medya aracilı̆̆ ile bireyin karşısına çıabileceği gibi kişinin bir başkasından bu konuda tavsiye alması ve aktiviteye teşvik edilmesi gerekebilir (Küçükibiş ve Eskiler, 2019).

Araştırma sonuçları ele alındığında, medyanın insanlar üzerinde etki bırakan ideal beden algısının zayıf ya da kaslı olmakla mümkün olacağı düşüncesinden uzaklaşabilmek adına bireylere, 
Emiroğlu, D., \& Özmaden, M. (2020). Üniversite giriş sınavına hazırlanan öğrencilerin sosyal fizik kayg1 düzeyinin incelenmesi. Journal of Human Sciences, 17(4), 1034-1046. doi:10.14687/ihs.v17i4.6046

sağlıklı bir yaşam sürebilmek için doğru beslenmenin ve bilinçli şekilde yapılan egzersizlerin önemi aşılanmalıdır.

Fiziksel aktivite, insanlanın kendisini iyi hissetmesini sağlar ve sağlıklı fiziksel gelişimleri için önemli bir rol oynar. Öğrencilerin SFK'yı daha az yaşamasına yardımcı olmak adına, fiziksel aktivitelere katılma konusunda cesaretlendirilmesi ve bu konuda uzman kişiler tarafindan bilgi alma olanağının sağlanması önerilebilir.

\section{Kaynaklar}

Arabac1, R. (2008). Relationship Between Social Physique Anxiety, Walking Activity and Body Composition in University Students. Sport Sciences, 3(3), 145-153.

Aston, E. (2018). The Relationships between BMI, Facebook Social Comparison, Body Shape Concerns and Social Physique Anxiety in Female Undergraduates.

Ballı, Ö. M. \& Aşçı, F. H. (2006). Sosyal Fizik Kayg1 Envanterinin Geçerlik ve Güvenirlik Çalışması. Hacettepe Journal of Sport Sciences, 17(1), 11-19.

Ballı, Ö. M., Kirazcı, S. \& Aşçı, F. H. (2006). Sporcu ve Sporcu Olmayan Bayanların Sosyal Fizik Kayg1 ve Beden İmgesinden Hoşnut Olma Düzeyleri. Gaz̧i Beden Eğitimi ve Spor Bilimleri Dergisi, 11(1), 9-16.

Bartlewski, P. P. (1996). Effects of aerobic exercise on the social physique anxiety and body esteem of female college students. Women in sport and physical Activity journal, 5(2), 49-62.

Chu, H. W., Bushman, B. A. \& Woodard, R. J. (2008). Social physique anxiety, obligation to exercise, and exercise choices among college students. Journal of American College Health, 57(1), 7-14.

Derman, O. (2008). Ergenlerde Psikososyal Gelişim. Adolesan Sağh̆̆ğ II Sempozyum Dižisi, 63, 19-21.

Doğan, T. (2011). Sosyal Görünüş Kaygisı Ölçeği’nin Psikometrik Özelliklerinin Ergenlerden Oluşan Bir Örneklemde İncelenmesi. İlköğretim Online, 10(1), 12-19.

Eren, Z. (2012). Spor Salonuna Giden Yetiskinlerin Yeme Tutumlar, Sosyal Fiæik Kayg ve Narsistik Yapılanmalar Arasindaki İlişki (Yüksek Lisans Tezi, Maltepe Üniversitesi, Sosyal Bilimler Enstitüsü, İstanbul).

Ersöz, G. (2011). Egzersize Katılım Güdüsü, Sürekli Optimal Performans Duygu Durumu ve Sosyal Fiziłe. Kayg Düzeyinin Egzersiz. Davranıs Basamağzna ve Fizilesel Aktivite Düzeyine Göre Irdelenmesi (Doktora Tezi, Ege Üniversitesi, Sağllk Bilimleri Enstitüsü, İzmir).

Hart, E. A., Leary, M. R. \& Rejeski, W. J. (1989). The Measurement of Social Physique Anxiety. Journal of Sport \& Exercise Psychology, 11(1), 94-104.

Küçükibiş, H. F. \& Eskiler, E. (2019). Fiziksel Aktivitelerde Sosyal Destek Ölçeği (FASDÖ): Türkçeye Uyarlama, Geçerlik ve Güvenirlik Çalışması. Sivas Cumburiyet Üniversitesi İktisadi ve İdari Bilimler Dergisi, 20(2), 117-127.

McLester, C. N., Hicks, C. S., Miller, L. \& McLester, J. R. (2018). An Investigation of the Differences between Perceived vs. Measured Body Composition, Social Physique Anxiety, and Overall Appearance Satisfaction among College Students. International journal of exercise science, 11(5), 957.

Özmaden, M. \& Yıldıran, İ. (2003). Futbola İlişkin Dışsal Etkenlerin Seyirci Saldırganlığı Üzerindeki Etki Düzeylerinin Araştırılması. Beden Ë̈itimi ve Sporda Sosyal Alanlar Kongresi, Ankara, (10-11 Ekim 2003), 188-198.

Pekdağ, F. \& Çoşkun, F. (2010). Üniversiteli Dansçıların Sosyal Fizik Kayg1 ve Beden İmgesinden Hoşnut Olma Düzeyleri. Pamukekale Journal of Sport Sciences, 1(2), 17-24.

Russell, W. D. (2002). Comparison of Self-Esteem, Body Satisfaction and Social Physique Anxiety Across Males of Different Exercise Frequency and Racial Background. Journal of Sport Behavior, 25(1), 74-90. 
Emiroğlu, D., \& Özmaden, M. (2020). Üniversite giriş sınavına hazırlanan öğrencilerin sosyal fizik kayg1 düzeyinin incelenmesi. Journal of Human Sciences, 17(4), 1034-1046. doi:10.14687/ihs.v17i4.6046

Sarıkabak, M., Karakulak, İ. \& Sunay, H. (2019). Lise Öğrencilerinin Sosyal Fizik Kaygı Durumları ve Duygusal Zeka Düzeylerinin Spor Yapma Değisskenine Göre İncelenmesi. SPORMETRE Beden Eğitimi ve Spor Bilimleri Dergisi, 17(3), 119-133.

Sarıoğlu, B., Güngörmüş, H. A. \& Işık, U. (2019). Serbest Zaman Engelleri ve Psikolojik İyi Oluş İlişkisi: Büro Çalışanları Örneği. 2. Uluslararası Rekreasyon ve Spor Yönetimi Kongresi, Bodrum, (11-14 Nisan 2019), 92-97.

Seki, T. \& Dilmaç, B. (2015). Ergenlerin Sahip Oldukları Değerler ile Öznel İyi Oluş ve Sosyal Görünüş Kayg1 Düzeyleri Arasındaki Yordayıcı İlişkiler: Bir Model Önerisi. Eğitim ve Bilim, 40(179), 57-67.

Soyer, F., Can, Y. \& Türkel, Ç. (2010). İlköğretim Çağı Öğrencilerinin Sportif Faaliyetlere Katıllım Düzeyi ile İletişim Beceri Düzeyleri Arasındaki İlişkilerin İncelenmesi. Sakarya Üniversitesi Eguitim Fakültesi Dergisi, 19, 73-88.

Sucu, N. (2018). Düzenli Egzersiz. Yapan ve Yapmayan Kadmlarn Baž Antropometrike Özellikler ile Beden Imgesi ve Sosyal Fizike Kaygr Düreyleri Arasmdaki İliskinin Incelenmesi (Yüksek Lisans Tezi, Aksaray Üniversitesi Spor Bilimleri Enstitüsü, Aksaray).

Şahin, A. (2018). Spor Salonuna Giden Yetişkinlerin Sosyal Fiziki Kayg1 Düzeylerinin İncelenmesi. Akdeniz Spor Bilimleri Dergisi, 1(1), 14-26.

Uğurlu, N. \& Akın, H. (2008). Muğla Sağlık Yüksekokulu Öğrencilerinin Beden Benlik Alg1sı ve Psikolojik Sıkınt Belirtileri ile İlişkisi. Anadolu Hemșirelike ve Sağhlk Bilimleri Dergisi, 11(4), 3847.

WEB. World Health Organization web site. https://www.who.int/news-room/factsheets/detail/obesity-and-overweight (13.12.2019).

Yaşartürk, F., Çelik, F., Kul, M., Türkmen, M. \& Akyüz, H. (2014). Beden Eğitimi ve Spor Yüksekokulunda Okuyan Öğrencilerin Sosyal Fiziki Kaygı Durumlarının İncelenmesi. International Journal of Sport Culture and Science, 2(Special Issue 1), 863-869.

\section{Extended English Summary}

In this study, it was aimed to determine whether the level of social physical anxiety of the participants varies according to gender, body mass index, active habit of doing sports, weekly frequency of doing sports and habit of eating fast-food.

In the social environment, people perceive that physical appearance constitutes an important part of the first impression. Reflected by social media and mass media; "the slim body" of women and "the muscular body" structure of men are made into as an accepted value. Society thinks that people who stay out of "the ideal body patterns" will be evaluated negatively.

Considering the impact of the media today, the physical appearance defects constitute an important problem for the individual in adolescence (Doğan, 2011). Adolescents often compare their appearance with the appearance of other people around them and they are evaluated by others (Seki and Dilmaç, 2015).

People's perception of their own physical appearance is as important as how others see and evaluate them. People want to make a positive impression on other people in their social environments and direct themselves according to that position. It is seen that some people give more importance to this issue and have anxiety compared to others (Pekdağ and Çoşkun, 2010).

These perceptions about the appearance in the society that are revealed and adopted, creates the pressure that people must reach certain physical measures that are unreal. When individuals can't reach these standards or go out of them, they may have false feelings and thoughts about the appearance that they aren't taken fancy by others and they are concerned about their body being evaluated by others. Anxiety about other people's negative evaluations about the physical image of people is defined as "Social Physical Anxiety" (Ersöz, 2011). 
Emiroğlu, D., \& Özmaden, M. (2020). Üniversite giriş sınavına hazırlanan öğrencilerin sosyal fizik kayg1 düzeyinin incelenmesi. Journal of Human Sciences, 17(4), 1034-1046. doi:10.14687/ihs.v17i4.6046

Hart et al. (1989) defined social physical anxiety as the transformation of one's feelings about his body when it comes to being evaluated by others.

In this period, when senior year in high school students are fully focused on the exam, they minimize their social activities and sit still at the desk for most of the day. At the same time, considering that they experience test stress and try to gain time from everything, their diet can be disrupted. The reason why private educational institutions are chosen for the study is that unlike normal high schools these institutions work for students on the weekends. The reason why the selected group is senior year high school students is that they are in a period that they can involuntarily gain or lose weight due to long-term and intensive exam preparation.

This study, which is based on the general survey model for the specification of social physical anxiety of students studying for university entrance exam, is a correlational survey model in terms of whether there are differences on the basis of gender, body mass index, active habit of doing sports, weekly frequency of doing sports, habit of eating fast-food.

For data collection, "Personal Information Form" and "Social Physical Anxiety Scale" have been used. Data of this study have been collected during the school year of 2018-2019 from the total number of 401 students studying senior year in high school (in the 12th grade), 216 of which are women $(53.9 \%)$ and 185 of which are men (46.1\%) who study for the university entrance exam at several private educational institutions affiliated with the Directorate of National Education at Efeler district of Aydin. According to the findings resulted from this study, it has been found that the levels of social physical anxiety of students display differences based on the variables of gender, body mass index, active habit of doing sports and weekly frequency of doing sports.

When the results of the research were examined, it was found that female students' social physical anxiety and negative evaluation expectation sub-dimension levels were higher than male students. However, when the physical appearance comfort sub-dimension level of the students is analyzed, it is seen that the average of the males is higher than the females. Trying to adapt to rapid physical development and dealing with these changes, teens in adolescence period, give importance to their bodies. Girls experience rapid growth and sexual development earlier than boys. Although this growth and development generally affects men's mental health positively, causes lower selfesteem, higher depression rate, anxiety and eating disorders in girls. The fact that female students' levels of Social Physical Anxiety and its negative assessment expectation sub-dimensions were higher than males may be due to the fact that females experienced more physical changes caused by adolescence.

According to the data obtained by calculating the students' body mass index, it was concluded that the average of physical appearance comfort sub-dimension of the students in the normal weight group was higher than the students in the overweight group. The reason is that it can be thought that individuals with normal weight are closer to the perception of physics, which is generally described, than overweight individuals. Therefore, it can be said that students who are in the normal weight range can be more comfortable and confident about their physics.

Although the non-sports students' expectation of social physical anxiety and negative evaluation sub-dimension levels are higher than the students doing sports, when the physical appearance comfort sub-dimension level is analyzed, it is seen that students who do sports have a higher average than non-sports students. It is an indispensable situation that people do sports for healthy life as well as to make their physics look better. For this reason, it can be interpreted that students who do not do sports are more concerned about social physics and negative evaluation, while students who do sports are more satisfied and comfortable with their physical appearance.

Considering the research results, to be able to live a healthy life, the importance of proper nutrition and conscious exercise should be impress on individuals in order to avoid the idea that the ideal body perception will be possible by being weak or muscular. 